\title{
OS ÁUSTRIAS E AS REFORMAS DAS ORDENS MILITARES PORTUGUESAS*
}

por

\section{FERNANDA OLIVAL}

Dept. de História - Universidade de Évora; CIDEHUS

RESUMEN: Este artículo analiza las juntas de reforma de las Órdenes Militares portuguesas bajo Felipe II y Felipe III con el fin de saber de qué modo la unión ibérica facilitó la comparación de las distintas órdenes peninsulares por parte de las portuguesas, y cómo éstas utilizaron este discurso para defender una mayor autonomía de las órdenes de Avís, Cristo y Santiago, que en esta época comenzaban a sentir que sus jurisdicciones se confundian con los intereses de la corona.

Palabras Clave: Órdenes Militares. Portugal. Monarquía Hispánica. Felipe II. Felipe III. Consejo de Órdenes.

ABSTRACT: This article analyses the reform committees of the Portuguese military orders under Philip II and Philip III, with the aim of determining the extent to which the union of the Spanish and Portuguese kingdoms allowed the Portuguese to bring the different peninsular military orders into closer equivalency. It also examines bow they used this discourse to defend greater autonomy for the orders of Avis, Cristo and Santiago, which felt their jurisdictions being increasingly undercut in this period by the interests of the crown.

KEY WORDS: Military orders. Portugal. Spanish Monarchy. Philip II. Philip III. Consejo de Órdenes.

Apesar do pedido de visitações e reformas feito num dos capítulos do Povo das Cortes de Tomar (cap. XVIII), a carta patente das graças e privilégios dada por Filipe $\mathrm{II}^{* *}$ a Portugal, assinada pouco antes do seu regresso a Castela, esta-

* Abreviaturas usadas ao longo do texto: AGS - Archivo General de Simancas; ANTT - Instituto dos Arquivos Nacionais / Torre do Tombo; BA - Biblioteca da Ajuda, Lisboa; BN - Biblioteca Nacional de Lisboa.

** Ao longo deste texto, para facilitar a comunicação, usam-se as designações castelhanas dos Áustrias. 
belecia: "Que nas ordens militares senão innouará nada do stado em que ao presente stão» (cap. XII). Ou seja, pelo que tocava ao pacto constitucional que alicerçava a anexação da Coroa portuguesa à dos Áustrias, não deviam ser introduzidas mudanças nas Ordens de Avis, Cristo e Santiago, nas quais desde 1551 os reis de Portugal eram governadores e perpétuos administradores, ainda que a Coroa viesse a recair em uma mulher ou em menor de sete anos. Não se pense, todavia, que a referida carta patente tenha sido um documento mal conhecido em Portugal antes de ser assinada pelo novo monarca. Como tinha a sua génese num diploma de $\mathrm{D}$. Manuel e era generosa com os portugueses; foi um instrumento essencial da propaganda desenvolvida a favor de Filipe II $^{1}$. Circulava desde pelo menos 1579 e nas Cortes de Tomar, o braço do Povo, da Nobreza e do Clero pediram que o seu conteúdo fosse outorgado².

Para quem desconheça o estado das Ordens Militares no início da década de 1580 e leia a patente das mercês de Filipe II, à primeira vista parece que sobre estas reinaria grande consenso; da união das Coroas nada de diferente do status quo habitual deveria resultar neste pelouro. Mas seria esse efectivamente o sentir dos diferentes sectores de portugueses e das próprias Ordens Militares em relação a estes institutos? Eis assim o problema central deste trabalho: apurar as imagens das Ordens Militares durante o período filipino e o sentido das mudanças introduzidas.

Quando Filipe II chegou a Portugal, havia poucos anos que as três Ordens Militares tinham sido objecto de alterações relevantes, que suscitaram algum alvoroço. D. Sebastião (1557-1578) impusera a obrigatoriedade de servir militarmente no Norte de África, nas armadas da costa e do oceano como meio para alcançar o simples hábito ou uma comenda; os serviços bélicos na Índia também eram admissíveis, mas exigiam-se mais anos e desempenhos excepcionais. Não permitiam, todavia, chegar às comendas. Apenas de 5 em 5 comendas que vagassem podiam os monarcas como governadores e perpétuos administradores prover a dita «quinta» comenda sem os requisitos dos «serviços de África» (uma sinédoque que, na linguagem comum, condensava desempenhos em qualquer dos pontos citados). Para além destas mudanças, D. Sebastião impôs a idade mínima de 18 anos, o que parecia um verdadeiro exagero, já que para professar em qualquer religião bastavam os 16 anos. $\mathrm{Na}$ realidade, com este requisito só se pretendia reforçar a ideia de que o cavaleiro de uma Ordem Militar portuguesa era um bom servidor da Coroa, pois normalmente a iniciação na actividade guerreira fazia-se mais cedo. Tudo isto era fortemente disciplinador e em prol dos interesses da Coroa. A imagem que se pretendeu incutir era a de que

1 Cf. BOUZA Álvarez, Fernando: «Documentos antigos e imprensas novas na pretensão ao trono português. Sobre a propaganda escrita de D. Filipe I», in Portugal no tempos dos Filipes: política, cultura, representaçöes (1580-1668), Lisboa, Cosmos, 2000, pp.39-60.

2 Cf. Patente das merces, graças, e privilegios, de que ElRey Dom Philippe Nosso Senhor fez merce a estes seus Reinos - $E$ adiante vai outra patente das respostas das Cortes de Tomar, Lisboa, Antonio Ribeiro, 1583 - cap. III do Povo; cap. I da nobreza e cap. I dos eclesiásticos.

Hispania, LXIV/1, núm. 216 (2004) 95-116 
a insígnia demonstrava curriculum militar revelante em favor da Monarquia. A bula de 18 de Agosto de $1570^{3}$, que sancionou a exigência dos serviços nas Ordens de Avis, Cristo e Santiago, introduziu simultaneamente dois outros tópicos que maximizaram a atracção exercida por estes símbolos: limpeza de sangue e de ofícios. Em Portugal esta última equivalia a Nobreza, tanto mais que nas habilitações não se inquiria da fidalguia, ao contrário do que sucedia em Castela.

No entanto, Filipe II nos primeiros anos após as Cortes de Tomar, e a propósito destas ${ }^{4}$, produziu uma grande inflação de hábitos. Só em 1582 entraram 205 cavaleiros na Ordem de Cristo. O novo monarca pagou fidelidades com estas insígnias, independentemente da natureza dos serviços. Importante era que os agraciados não tivessem servido D. António.

Ainda sob Filipe II os apelos a reformas tornaram-se preementes. Pelo menos em 1584, o assunto era já objecto de referência nas cartas régias 5 . O elevado número de cavaleiros, o não celebrar da capítulos gerais há muito tempo ${ }^{6}, o$ modelo que ofereciam as Ordens castelhanas, o velho e tremendo conflito entre as Ordens de Avis e Santiago e os Ordinários: tudo isto impelia a rever o estado das portuguesas.

\section{A Junta de REForma da ORdem de CRISTO do TEMPO de Filipe II.}

Em Dezembro de 1589, concluía os seus trabalhos uma junta de reforma da Ordem de Cristo. Nesta terão participado ao todo oito pessoas, embora, até ao momento, apenas tenham sido identificadas quatro: o Conde de Idanha, o Conde de Sabugal, Miguel de Moura e António de Almeida, na sua qualidade de Deputado da Mesa da Consciência, a quem coube o papel de secretário ${ }^{7}$. Terão sido todos nomeados por Filipe II para este efeito, o que não terá sido um pormenor despiciendo. Seriam, certamente, pessoas da confiança política da realeza. Para isso serviam também as juntas.

Desconhece-se quando se terão iniciado os trabalhos. Pelo que produziram, terão sido relativamente demorados. Sabe-se apenas que as sessões não terão sido contínuas, como era usual nestes casos: «fizeramse as juntas necessarias,

3 Cf. "Ad Regie Maiestatis», in Corpo Diplomatico Portuguez contendo os actos e relaçōes politicas $e$ diplomaticas de Portugal com as diversas potencias do mundo desde o seculo XVI até os nossos dias, ed. de José da Silva Mendes Leal, t.XI, Lisboa, Typ. da Academia Real das Sciencias, 1898, pp.630-640.

4 Para as Cortes de Tomar ter-se-á recomendado que não fossem eleitos procuradores adeptos de D. António Prior do Crato - cf. Silva, Francisco Ribeiro da, introd. e coord., Filipe Il de Espanha, rei de Portugal (colectânea de documentos filipinos guardados em Arquivos Portugueses), Vol.I, Zamora, Fundación Rei Afonso Henriques, [D.L. 2000], p. 47.

5 Cf. ANTT, Corpo Cronológico, Parte 1, Mç. 111, doc. 104.

6 O último capítulo geral da Ordem de Cristo datava de 1573; o de Santiago de 1564 e o de Avis de 1538.

7 Cf. AGS, Secretarias Provinciales - Portugal, L ${ }^{\circ} 1481$, fl.257v. 
ainda que com algus intervalos, pola concurrencia d'outros negócios» ${ }^{8}$ - registou a certa altura o secretário.

Apesar de não ter tido consequências imediatas, a actividade desta instituição foi importantíssima. Ainda no dizer da mesma personagem, nas reuniões da junta «se tratârão as materias, que se entendeo mais convinhão de presente ao bem, reformação, E conservação desta ordem, assi na regra, como nos statutos, diffinções antigas, E bullas dos santos padres, começando de seu principio, com a diligencia devida»?. No fim, foi elaborado um livro manuscrito que resumia os trabalhos e que foi dividido em quatro partes para maior clareza. Sem esta obra, seria difícil compreender os estatutos da Ordem de Cristo, saídos dos definitórios de 1619 e impressos em 1628. Acresce que este texto permite traçar uma radiografia do conjunto da Ordem tomarense no final dos anos de 1580 , que é rara noutras fontes.

A primeira parte do texto incidia sobre os cavaleiros e dignidades da Ordem; a segunda sobre os recursos materiais da milícia e respectiva gestão; a terceira sobre a jurisdição eclesiástica da mesma; por fim, a última era muito breve e inventariava privilégios e comendas desta insígnia.

O livro de 153 fólios começava por afirmar o estatuto religioso da Ordem e estabelecia que o objectivo desta milícia era «defender, exaltar, E ampliar sua Sancta fé» ${ }^{10}$. A Ordem de Cristo era ali representada como um corpo activo, e esta ideia era por diversas vezes vincada, por oposição aos religiosos de vida meramente contemplativa. A sua vocação direccionava-se para a peleja em prol da Fé de Cristo, "offerecendo as vidas, recebendo mortes, seminario tambem he de triunfantes martyrios» ${ }^{11}$. Aos cavaleiros lembrava-se textualmente que não deviam pretender a filiação pelo simples interesse temporal na comenda ${ }^{12}$.

Ao longo deste texto insistia-se muito na vertente do combate como um factor de identidade desta Ordem. "A primeira, E principal obrigação» que era apontada ao cavaleiro era esta. Devia "pelejar contra os inimigos da Cruz de Jesu Christo, assi pera augmentar Sua sancta fé, como pera a defender, E conservar, Estando sempre promptos com suas armas pera favorecer. E servir a sancta igreja catholica com proposito de dar a vida por sua defensão, E offerecela por seu augmento, todas as vezes que o mestre, ou governador lho mandar, porque este he sómente o fim $\mathrm{E}$ intento desta ordem militar» ${ }^{13}$. Era assim que se justificava $o$ gozo das rendas auferidas, que não deviam - de acordo com a letra do texto - ser desperdiçadas em luxúrias e jogos, deixando o seu detentor menos poderoso para cumprir as suas obrigações. Quem se escusasse a combater, sem causa legítima, pecava contra a obediência, o voto essencial dos cavaleiros nesta época.

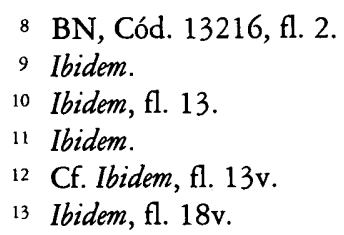


Ainda neste contexto era dado muito relevo à cruz como divisa de uma Ordem dita de Jesus Cristo, o que se considerava ser um título muito especial. A cruz foi desenhada a cores nas primeiras páginas do texto e devia servir de modelo, inclusive no tamanho, para os hábitos que todos deviam trazer nas roupas exteriores. Com intuitos pedagógicos ensinava-se a descodificar a simbologia da mesma: «de cor vermelha aberta em branco, em significação da chaga, que foi aberta no sanctissimo lado de Christo, donde sahio sangue E agua em sinal da nossa redempção» ${ }^{14}$.

A par da ideia do combate como ponto identitário, nesta junta insistia-se muito no rei como governador e perpétuo administrador da Ordem. A ele era dirigido o voto de obediência. Cabia-lhe um lugar de comando. Era também uma forma de dar projecção à Ordem, designadamente através da Capela Real.

A esta instituição concedia-se um espaço importante na Ordem, apesar da junta pretender reforçar o papel de Tomar. Por exemplo, propôs um orago para a Ordem de Cristo, à semelhança do que ocorria nas restantes milícias. Apontouse que devia ser assinalado a 14 de Setembro, dia da Exaltação da Cruz e encerrava com a seguinte observação: «E que se celèbre esta festa na capella de S. Magde. onde averà vespera, E Missa solemnes do Dayão, nas quaes pedem a Sua magestade queira estar presente com todos os Comendadores, E cavalleiros com seus mantos brancos; E que aja por bem o conteudo neste titolo»! 15 .

Esta apropriação simbólica da Capela Real pelas Ordens ia ao ponto de recomendar que ali estivessem sempre capelães pertencentes às três Ordens, com o objectivo de confessarem e sacramentarem os cavaleiros e que deviam ser «bem expertos nas regras, E statutos dellas» ${ }^{16}$.

No período posterior à Restauração, acentuar-se-ia o lugar subalterno do Mestre porque dependente de Roma ${ }^{17}$. Nesta fase, a representação do administrador perpétuo das Ordens ainda não era essa. Acima de tudo irradiava poder, que devia reverter a favor do engrandecimento destes institutos.

Nesta junta, os serviços e os locais onde se deveriam realizar tendo em vista a obtenção de um hábito, e sobretudo de uma comenda, foram assuntos muito discutidos. Em 1589, no essencial, reforçava-se aquilo que interessava à realeza, designadamente a importância dos serviços para atingir as distinções das Ordens Militares.

Começou-se por abordar o problema dos hábitos. A este propósito a junta foi branda. Apelava à reforma das orientações fixadas pelos Papas dos inícios dos anos de 1570, "porque não he contra a instituição desta ordem, E seu intento, as pessoas que a ella de novo se receberem polo habito sómente, não terem os ditos serviços, posto que despois de a professarem, tenham obrigação de comprir com elles, quando S.Magestade E seus sucessores lho mandarem. E

14 Ibidem, fl. 16v-17.

15 Ibidem, fl. 42.

16 Ibidem, fl. 45.

17 Cf. Olival, Fernanda: As Ordens Militares e o Estado Moderno: honra, mercê e venalidade em Portugal (1641-1789), Lisboa, Estar, [D.L.2001], pp. 39-42.

Hispania, LXIV/1, núm. 216 (2004) 95-116 
a assi pareceo, que daqui em diante, possão S.Magestade E successores livremente fazer merce do habito regular desta ordem de Christo, a pessoa que lhes parecer, por quaesquer serviços, de qualquer qualidade $\mathrm{E}$ tempo que sejão, ainda que nã sejão de guerra cõtra infieis, E sendo taes pessoas de que a ordem receba honra $\mathrm{E}$ proveito» ${ }^{18}$.

Em 1589 e no que respeita ao hábito, este pedido resumia a situação corrente. De facto, pouco se cumpriu do estabelecido entre 15.70 e 1575. Desde logo, a derrota de Alcácer-Quibir e a disputa pelo trono terão feito esquecer os preceitos normativos que impunham serviços militares. A obrigação de combater os infiéis representava uma grande exigência que poucos estavam dispostos a cumprir. Nos anos de 1570 e 1580 subsistiu essa tensão entre, por um lado, as imposições estatutárias conseguidas a instâncias dos reis-Mestres, reavivando os ditames da bula fundadora da Ordem de Cristo, a da união dos três Mestrados à Coroa e a simples tradição combatente destas milícias, e por outro, o interesse social em receber estas distinções com facilidade. A partir da conjuntura de 1580 , será este último a impor-se. Em 1592, pelo alvará régio de 11 de Janeiro ${ }^{19}$, na sequência de um breve pontifício do ano transacto, que dava a Filipe II faculdade para corrigir os estatutos das Ordens, foi abolida a obrigação "dos serviços de África» para receber o simples hábito. A partir de então, consagrou-se, na prática, o princípio que o ícone das Ordens era atribuído por quaisquer serviços próprios ou não (podia também advir de acções de terceiros, ainda que não fossem parentes). A natureza do desempenho deixou, assim, de ser relevante. A Coroa acabou também por sair beneficiada, pois tanto podia abertamente remunerar com as insígnias das três Ordens Militares afazeres políticos, como administrativos, ou outros que entendesse necessários. $O$ hábito impunha-se cada vez mais como forma de retribuição, com valor simultaneamente económico e honorífico.

No que respeita às comendas, o debate da junta foi muito prolongado. Além do tempo, os locais onde se deveriam realizar os serviços foram tratados com muita minúcia, considerando o tipo de preceptorias em causa ${ }^{20}$.

Foi decidido que uma "comenda nova» decorria de três anos de serviço, enquanto para as outras dois seriam suficientes ${ }^{21}$.

Aconselhava-se, todavia, que para todas as comendas se tornasse indispensável carta régia de licença para serem servidas, mesmo quando o candidato

18 Cf. BN, Cód. 13216, fl. 53v-54.

19 Publicado por Carvalho, Lourenço Pires de: Enucleationes Ordinum Militarium, II, Ulyssipone, apud Michaelem Deslandes, 1699, Enucl.III, compr.VI, § 382.

20 Havia na Ordem de Cristo "comendas velhas» e «comendas novas». As primeiras correspondiam às legadas pelos Templários. As restantes foram erectas no reinado de D. Manuel, com autorização Papal.

21 . Dois votos, todavia, «forão em parecer, que não Se devia fazer differença no tempo de serviço antre as comendas novas $\mathrm{E}$ antigas porque pois huãs $\mathrm{E}$ outras se hão de vencer militando, he justo, $\mathrm{E}$ conveniente, que se venção com o mesmo tempo, E não differente», BN, Cód. 13216, fl. 60-60v. 
pretendia fazê-lo nas galés e armadas ${ }^{22}$. Só assim se permitia culminar os interesses da Monarquia nas Ordens Militares. Era também um meio eficaz de controlo social, pois - se assim fosse - deixaria de ser possível requerer comendas sem serviços não autorizados previamente. Além disso, tal permissão tornar-seia em mais uma ocasião para fazer mercê, por parte do centro político.

Para as «velhas», exceptuadas as quintas comendas, rejeitava-se com clareza a possibilidade de serem concedidas livremente: "Muitas reZões persuadem, os statutos dos santos padres sobreditos [Pio V e Gregório XIII] serem mais conformes ao que convem ao serviço E Louvor de Deus, E bem da ordem, do que o foi o antigo costume, que elles revogarão (...) E quando assi fora, fóra de rezão seria, que paguem os Reis soldo de sua propria fazenda aos fronteiros, pera defensão dos lugares conquistados das partes d'Africa $\mathrm{E}$ Jndia, $\mathrm{E}$ as comendas $\mathrm{E}$ rendas desta ordem de Jesu Christo, que são bens ecclesiasticos applicadas pelos sanctos padres a este mesmo exercicio militar contra infieis, se dèm $E$ entreguem a quem nunca offendeo mouros, nem defendeo christãos. (...) Que o intento desta ordem, seja não sómente defender, mas conquistar, disse claramente ElRei Dom Manoel de boa memoria, naquella sua diffinção. 51. quando por esta causa applicou certas comendas velhas, pera os, que em Africa servissem quatro anos continuos (...). E o mesmo nome, de ordens militares, diz que não São de paz, se não de guerra» ${ }^{23}$. Com excepção de um voto, todos advogaram que as comendas velhas deviam ser providas em quem tinha serviços contra os infiéis, fossem eles feitos em África, na Índia, nas costas do Reino e galés, nos navios de alto bordo no Oceano. $\mathrm{O}$ importante era que fosse «sempre guerra contra Jnfieis ainda que sejão Luteranos. E que não deve s.Md per outros alguns Serviços, que não Sejão os sobreditos, prover a pessoa alguã destas comendas, nem dispensar contra o sobredito, por ser conforme aos statutos apostolicos» ${ }^{24}$.

A maioria dos votos foi também de parecer que nos serviços das armadas, fossem apenas válidas as diligências contra corsários e piratas não católicos, para se ser fiel à instituição da Ordem de Cristo, que a vocacionara à luta contra o infiel. Entendia esta junta que «a obrigação de defender estes Reinos, E segurar o mar dos piratas, he particular do patrimonio real, ao qual são applicados certos direitos por este respeito ${ }^{25}$, donde não fazia sentido abalizar genericamente estes serviços para receber distinções das Ordens Militares ${ }^{26}$.

22 Cf. Ibidem, fl. $58 \mathrm{v}-59$

23 Ibidem, fl. $54 \mathrm{v}-55 \mathrm{v}$.

24 Ibidem, fl. 55v.

25 Ibidem, fl. 56.

26 Um voto foi defensor da observância da bula como estava «vista a urgente necessidade, que ao presente ha de se usar della, polos muitos corsairos que ha catholicos» (Ibidem); o outro voto manifestou-se a favor da aplicação da bula apenas às comendas velhas e às de Santiago e Avis; às novas, não (Ibidem, fl. 56-56v). De acordo com esta junta, as pensões em comendas, essas sim, podiam ser dadas por serviços "em guerra per mar, ou per terra, em qualquer parte destes Reinos ainda que não seja contra Jnfieis, que por serem pensões, $E$ não comendas, não tem tão preçisa obrigação de comprir com o intento da jnstituição das ordens militares» (Ibidem, fl. 67v). 
Sobre as comendas novas, a discussão foi ainda mais cuidada, sobretudo no que respeita aos espaços onde deviam ocorrer os serviços.

Começou-se por lembrar que, quando D. Manuel impetrou estas comendas, fê-lo declarando que tinha guerra contra os inféis, «não somente em Afri$\mathrm{ca}$, mas em Guinè, Arabia, persia, E na Jndia ${ }^{27}$, mas como sempre se serviram no Norte de África e não noutros locais, assim deviam continuar. "[P]areceo, que este custume era fundado em boa rezão, polas muitas que ha, pera este Serviço contra Jnfieis Ser mais necessario nos Lugares de Africa, pola muita necessidade que tem de muitos fronteiros pera sua defensão: que por nelles aver pouca occasião, pera as pessoas, que a elles vão, se poderem melhorar em fazenda, E riquezas, não accodem a ellas comummente pessoas de honra, E qualidade: que em semelhantes forças montão muito por sua authoridade, E esforço» ${ }^{28}$. A ideia seria atrair nobreza de sangue, fidalguia, para o Norte de África, onde se iriam habilitar para receber comendas novas, servindo com homens, cavalos e criados, a expensas de cada um. Este chamariz criaria estímulo: «com o que todos ficão mais animosos, $\mathrm{E}$ a guerra Sempre ordenada pera melhor successo» ${ }^{29}$. No entender desta junta; na Índia não haveria essa necessidade: «O que nas partes da Jndia se pode Escusar, onde pola muita riqueza que nellas ha, variedade de comercios, Largueza de mar, E terra, a industria dos homens se satisfaz. A cujo exemplo acodem destes reinos cada anno tanto numero de nobres, $\mathrm{E}$ mais gente de toda a sorte, que sem speranca de comendas novas, defendem o ja conquistado, conquistão de novo, vencem guerras, amplião o muito faelice stado destes reinos, não por isso menos merecedores dellas: mas pola sperança das antigas, E outras merces, que recebem de S. Mgd. E pola disposição da terra, estão nella com maior satisfação» ${ }^{30}$. Com base nestes princípios, defendia-se que as comendas novas deviam ser obtidas apenas na guerra de África, nos locais estipulados pela Coroa. Quer a Índia, quer as armadas deviam ser excluídas.

Ao contrário do que se vinha a fazer, esta junta tratava de acentuar ainda mais as diferenças entre comendas novas e velhas, de modo a que a Monarquia pudesse tirar maior partido destas benesses.

Era tal a inclinação desta junta aos interesses da Coroa que se admitia a hipótese da quinta comenda ser livremente provida pelo rei enquanto mestre, independentemente de ser das novas ou das velhas. Considerava-se também que o monarca devia poder dispor livremente de outros bens das Ordens para agraciar servidores exímios, sem ter em linha de conta o tipo de desempenhos: «E porque não he de menos obrigação a satisfação, que os Reis devem aos que os servem na paz, ajudandose de seus serviços no governo de seus Reinos, sem o qual se não pode sostentar fora delles a guerra, E conquista dos Jnfieis (...) a

27 İbidem, fl. 57.

28 Ibidem, fl. 57-57v.

29 Ibidem, fl. $57 \mathrm{v}$.

30 Ibidem.

Hispania, LXIV/1, núm. 216 (2004) 95-116 
que o patrimonio real, por muitas outras, que tem não pode accodir» ${ }^{31}$. Porque as Ordens estavam vinculadas à guerra contra o infiel, tornavam-se um complemento aos recursos da Coroa. E assim também se justificavam as pensões em comendas até $1 / 3$ dos frutos ${ }^{32}$.

Quanto às comendas e bens da Mesa Mestral, a junta apontava que o governador podia usá-los livremente, mas impunha limites quanto a serem concedidos como comendas pelo rei ${ }^{33}$. O fito seria não permitir que por alheação se reduzisse excessivamente, e de modo irreversível, o pecúlio destinado ao Mestre. Relembra-se, também, que no tempo de D. Sebastião se fixara que o perpétuo administrador das Ordens estava isento de pagar impostos (três quartos) pelos bens das Ordens que usufruía ${ }^{34}$.

Embora as comendas tenham sido o assunto que mais demorada atenção mereceu nesta junta, também ocupou um lugar importante as condições exigidas aos candidatos que deviam ingressar nestes institutos. Recomendava-se nobreza até aos quatros avós, legitimidade de nascimento, ausência de crimes, património suficiente para não viver de forma vexatória, não ser filho, nem neto de hereges, nem de judeus ou de mouros, não provir de pais e avós mecânicos. Quem contava com um pai que exercera ocupações manuais só the era permitida a insígnia se, pelos "Estremados Serviços», estivesse previamente inscrito nos livros de Sua Majestade como fidalgo. O mesmo devia acontecer com o filho bastardo de nobre, mesmo que não tivesse um curriculum de afazeres. Nestas duas circunstâncias, admitia-se que se lançasse o hábito sem dispensa. Para quem era só neto de mecânico, bastavam os serviços; o foro da Casa Real tornava-se despiciendo ${ }^{35}$. Propunha-se, assim, uma hierarquização dos hábitos num patamar superior ao do foro máximo, dado pela Coroa.

A exaltação dos serviços e consequente complacência atingia o seu ponto extremo em relação aos moradores do Norte de Africa: deviam ser dispensados e receber a insígnia de Cristo, e mesmo uma comenda, se tivessem serviços, ainda que o próprio candidato tivesse raça de mouro «ou algu foSse mouro, que novamente se converteo $\mathrm{E}$ fez Christão ${ }^{36}$; o mesmo devia acontecer se àquelas máculas se juntasse a mecânica.

Outro ponto a destacar dos muitos assuntos abordados nesta junta diz respeito à «jurisdição secular que a ordem tem em algũs lugares» ( $3^{a}$ Parte, tít.8). Começou-se por registar por escrito que a jurisdição «secular E temporal dos lugares desta ordem, foi de principio sempre dos Reis, assi $\mathrm{E}$ da maneira, que a tem em todos os lugares de seus Reinos, E senhorios. Mas polos merecimentos dos mestres E cavalleiros della, foi antigamente concedida per os mesmos Reis

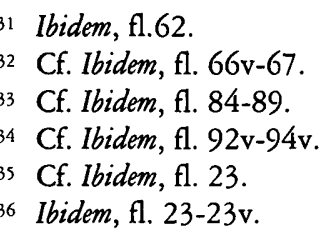


á ordem ${ }^{37}$. É de realçar esta postura do rei como fonte de direitos depois doados à Ordem. Analisaram-se sobretudo os casos das Ouvidorias de Tomar e Castelo Branco. Até às Cortes de Almeirim (1544) tiveram os ouvidores legitimidade para receber apelações nos casos cíveis, dos quais não se podia recorrer ao monarca. Assim era, ao que parece, desde o reinado de D. Fernando (1373). Apenas os feitos crimes podiam rematar nas mãos dos reis ou dos seus tribunais. Por uma carta de 26 de Julho de 1544, D. João III limitara tais poderes: os ouvidores do Mestrado ficavam apenas com as apelações que coubessem na sua alçada; as restantes deviam ser endereçadas a quem direitamente pertencessem. Acresce que, após a anexação à Coroa, ouvidor e corregedor passaram a coincidir na mesma pessoa, sem muitas vezes tirarem duas cartas de provimento. Considerava a junta que tal situação prejudicava a Ordem e que o reimestre não podia alterar a norma antiga sem recorrer ao capítulo geral. Apontava-se que a união à Coroa não devia redundar em diminuição, mas em acrescentamento e por essa razão se interferia neste assunto.

Foi dedicado também algum tempo ao modo de prover os benefícios eclesiásticos da Ordem ${ }^{38}$.

Ao longo do texto, de vez em quando fazia-se referência a parágrafos específicos da definição antiga, saída do capítulo geral de $1503^{39}$. Foi seguramente um dos textos lido pelos presentes e que lhe terá servido de guia na abordagem de alguns tópicos. É também muito provável que se tivessem consultados os definitórios do capítulo da Ordem de Cristo reunido em Santarém, em 157340. Foram duas das grandes matrizes com base nas quais se trabalhou.

O resultado desta junta, que transformava a Ordem de Cristo num lugar distinto para os que serviam contra os infiéis sob a grandiosa tutela do rei-mestre, não foi posto em prática. O livro feito foi encerrado com o estatuto de consulta e assinado pelo secretário. Foi parar a Castela. Por carta régia de 23 de Maio de 1608 foi de novo devolvido à Mesa da Consciência ${ }^{41}$, não se sabe exactamente com que intuitos. Nos começos de 1612 , é possível que se tenha pensado em mandá-lo imprimir, embora a ideia não tenha sido concretizada ${ }^{42}$. A junta não foi, porém, trabalho em vão. Os seus conteúdos seriam posteriormente retomados.

\section{EPISÓDIOS DE UM SEGUNDO MOMENTO DE MUDANÇAS}

Talvez já no início de 1611, a mando de Filipe III, teria sido discutido no Conselho de Estado, em Portugal, a hipótese de se efectuarem capítulos gerais

37 Ibidem, fl. 114

38 Cf. Ibidem, fl. 119-128v.

39 Cf. Ibidem, fl. 22v, 42v, 43, 73v, 77, passim.

40 Cf. Ibidem, fl. $104 \mathrm{v}, 117 \mathrm{v}$, passim.

41 Cf. ANTT, Ordem de Avis / Convento de S. Bento de Avis, $\mathrm{L}^{\circ} 22, \mathrm{fl} .3 \mathrm{v}$.

42 Cf. BA, 51-VIII-13, fl. 269-270.

Hispania, LXIV/1, núm. 216 (2004) 95-116 
das Ordens Militares e ainda algumas reformas a introduzir nestas: mudança dos conventos para o Norte de África; atribuir hábitos apenas por grandes serviços e a pessoas com todas as qualidades. Em Abril do citado ano, o Vice-rei dava conta do resultado ao Conselho de Portugal: os conselheiros mostraram-se favoráveis a reformas, mas consideravam difícil fazer capítulos gerais «polla multidão que ha de Comendadores, distançia dos lugares em que vivem, E pobreza de muitos delles»43; sugeriam, como alternativa, juntas de sete pessoas, incluindo no cômputo de cada uma o prior-mor do Convento respectivo e o comendador-mor. Do que se resolvesse seria dada conta ao rei e só depois se pediria confirmação à Santa Sé, o que faria com tudo tudo fosse cumprido, como se tivesse sido acordado em capítulo geral. A ideia de reformas teria sido bem acolhida por se achar que as Ordens Militares estavam esquecidas e que ninguém sabia já «o que ha de rezar, nem os mantos que ha de trazer, nem tempos em que se hão de confessar $\mathrm{E}$ comungar, nem as mais çeremonias $\mathrm{E}$ obrigações particulares que ha». Considerava-se que seriam estes aspectos «os pontos prinçipaes que se devem trattar nesta junta» ${ }^{44}$. Os conselheiros teriam também manifestado a sua anuência a um maior rigor na atribuição dos hábitos e à qualidade dos agraciados; quanto ao resto, eram desfavoráveis: mudar os conventos implicava muita despesa; obrigar os cavaleiros a morar no Norte de África também parecia desnecessário, tanto mais que as comendas podiam ser servidas em armadas.

Na sequência desta consulta do Conselho de Portugal, em 1612, uma carta régia de 28 de Outubro, preconizou a realização de juntas com intuitos reformadores, em cada uma das Ordens: para que «as ditas miliçias se restituão á seus verdadeiros principios, E a major observancia de seus Estatutos, E diffiniçoins» ${ }^{45}$. Na de Cristo, apontava-se que devia ser analisado o livro de 1589 , que fora remetido a Portugal.

Essas juntas deviam reunir-se em Lisboa e ser compostas pelos citados sete membros. Cabia ao Vice-rei escolher os cavaleiros e comendadores, que deviam ser "pessoas de qualidade, E que tenhão zelo, E notiçia das cousas de Sua Ordem" ${ }^{46}$. Ao contrário da junta anteriormente referida, nesta pontificavam pessoas escolhidas pela respectiva ligação às Ordens Militares. Filipe III não as nomeou uma a uma.

Do que fosse acordado, deviam ser redigidos textos a analisar pela Mesa da Consciência. Cabia a esta fazer consultas e enviá-las ao monarca.

Desde logo, Filipe III indicava quando poria tudo em prática: «porque meu jntento he que à resolução que nesta materia se tomar se execute quando ora (prazendo a Deus) for á esse Reyno ${ }^{47}$. Praticamente desde o início do reinado que se aguardava a deslocação do monarca. É natural que estes acontecimentos fossem projectados no âmbito de tal evento.

43 AGS, Secretarias Provinciales - Portugal, L ${ }^{\circ} 1481, \mathrm{fl} .257$.

44 Ibidem, fl. $257 \mathrm{v}$.

45 Ibidem, fl. 3.

46 Ibidem.

47 Ibidem, fl. $3 \mathrm{v}$. 
A junta da Ordem de Avis começou nos inícios de Fevereiro de 1613 e durou até 8 de Março do ano seguinte - 14 meses ao todo. É a que melhor se conhece, pois dela resta muita documentação.

Os sete congregados foram: D. Lopo de Sequeira Pereira, Prior-mor do Convento; D. Luís de Lencastre, comendador-mor; D. Jerónimo Coutinho, comendador de Olivença; D. Gonçalo da Costa, comendador de S. Vicente da Beira; Diogo de Castilho, comendador de Mora; D. Carlos de Noronha, comendador de Mourão; João Gomes Leitão, simples cavaleiro e Corregedor da Corte, que foi o secretário ${ }^{48}$. Presidiu o Prior-mor.

É possível esboçar o cronograma aproximado dos grandes assuntos tratados:

\begin{tabular}{|c|c|c|c|}
\hline ANO & MÊS/DIA & CONSULTA: ASSUNTO & $\begin{array}{l}\text { RESPOSTA RÉGIA: } \\
\text { ASSUNTO }\end{array}$ \\
\hline 1613 & Fev.- 29? & -Concordata & \\
\hline 1613 & Mar.- 03 & -Estatutos - $1^{\circ}$ Caderno & \\
\hline 1613 & Abr. -26 & -Concordata & \\
\hline 1613 & Jun.- 19 & -Pontificais & \\
\hline 1613 & Jul.- 03 & -Estatutos - $1^{\circ}$ Caderno &.. \\
\hline 1613 & Agt.- 14 & -Concordata & . \\
\hline 1613 & Agt.- 29 & -Benefícios simples & \\
\hline 1613 & Set.- 02 & -Estatutos - $1^{\circ}$ Caderno & \\
\hline 1613 & Set.- 04 & & -Pontificais \\
\hline 1613 & Set.- 04 & (1) & $\begin{array}{l}\text {-Concordata; } \\
\text {-Consultas não } \\
\text { vão à MC. }\end{array}$ \\
\hline 1613 & Set.- 12 & -Estatutos - $2^{\circ}$ Caderno & \\
\hline 1613 & Dez.- 11 & -Concordata & \\
\hline 1613 & Dez.- 11 & -Reparação das Igrejas da Mesa Mestral & \\
\hline 1614 & Jan.- 15 & -Estatutos $-4^{\circ}$ Caderno & 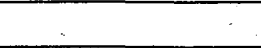 \\
\hline 1614 & Mar.- 08 & -Estatutos - $3^{\circ}$ Caderno & 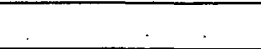 \\
\hline 1614 & Mar.- 08 & -Estatutos - último Caderno & $\therefore$ \\
\hline 1614 & Mar.- 08 & $\begin{array}{l}\text {-Última consulta: síntese; Conselho } \\
\text { Ordens separado da MC }\end{array}$ & 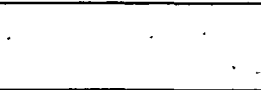 \\
\hline
\end{tabular}

MC - Mesa da Consciência e Ordens

A reforma da regra terá sido o assunto principal desta junta. Contudo, a questão da concordata ocupou também muito os presentes. Era um tema forte na conjuntura em análise. Não foi sem razão que se tratou do primeiro assunto abordado.

48 Sobre esta composição ver, também, Regra da Cavallaria e Ordem Militar de S. Bento de Avis, Lisboa, Yorge Royz, 1631, tít.I, cap. VII.

Hispania, LXIV/1, núm: 216 (2004) 95-116 
Tal questão decorria de um longo conflito entre a Ordem de Avis e o Arcebispo de Évora. Durava desde o final do século XII ${ }^{49}$, embora os pontos de atrito tenham variado ao longo do tempo. As outras Ordens Militares, sobretudo Santiago, tinham também problemas com os poderes diocesanos. Neste caso, a concordata abrangia os três Mestrados e parece ter resultado de uma junta de clérigos. Em 1613, a Ordem de Avis sublinhava que estava isenta da jurisdição e visitas dos Ordinários. Cabia a estes, e no entender da junta, apenas: "confirmarem os apprezentados nos benefiçios, $\mathrm{E}$ dar ordeñs sacras aos frejres, $\mathrm{E}$ os santos Oleos, vizitar os freguezes, E dar-lhes o sacramento da Confirmação por lhe largar a Ordem a $3^{\mathrm{a}}$ parte dos dizimos, ficando em tudo ò mais izenta da Sua Jurisdição, assi por Sua Instituição, como por muitos breves Apostolicos» ${ }^{50}$. Como havia pouco tempo que os Ordinários tinham redigido tal concordata, na qual se tratava sobretudo do direito de visitar igrejas e instituições das Ordens e que o Arcebispo de Évora e o bispo de Elvas aceitavam, a junta de Avis propôs que não fosse ratificada por Roma nem cumprida, tanto mais que não tivera a sanção do capítulo geral ${ }^{\mathrm{SI}}$. Este pedido acabou por ser acompanhado de um protesto feito pelos conventuais de Avis, redactado em 23 de Outubro de 1613, e de outro subscrito pelos comendadores, cavaleiros e beneficiados desta insígnia.

Apesar da Junta de Avis se ter iniciado nos começos de Fevereiro, apenas a 3 de Julho se fez consulta a enviar o primeiro caderno da regra. Para a elaboração do mesmo, que hoje se desconhece, terão sido manuseados diversos documentos. É possível que tenha implicado muito tempo de elaboração. Apenas resta hoje identificada a consulta que acompanhava o caderno. Do seu conteúdo depreende-se com clareza que esta parte da regra abria com uma história da «origem e antiguidade» da Ordem. Pressupõe-se que teria sido escrita com intuitos legitimadores ${ }^{52}$. Elencavam-se também os mestres $e$ as dignidades da milícia.

Em 2 de Setembro uma segunda consulta sobre este $1^{\circ}$ caderno insistia na urgência das reformas e na feitura de capítulo geral para o efeito. Pedia-se que fosse mandada visitar. Tal facto seria um requisito prévio à feitura do capítulo geral, que devia ocorrer quando Filipe III viesse a Portugal. «E quando se isto dilate, pedimos a V.Mgd. cometa seus poderes a hũa pessoa da Ordem que o faça (...) E se possa tirar algũ fruto do que se vaj fazendo nesta Junta» ${ }^{53}$. A jun-

49 Sobre o conflito nos seus inícios, cf. VILAR, Hermínia Maria Vasconcelos: «A diocese de Évora e a Ordem de Avis: dois poderes em confronto na centúria de duzentos», in As Ordens Militares em Portugal e no Sul da Europa: actas do II Encontro sobre Ordens Militares, Lisboa, Colibri. Câmara Municipal de Palmela, 1997, pp.271-284; Idem, As dimensões de um poder: a diocese de Évora na Idade Média, Lisboa, Estampa, 1999, pp. 252-275.

so ANTT, Ordem de Avis / Convento de S. Bento de Avis, $\mathrm{L}^{\circ} 22$, fl. 6.

51 Ibidem, fl. 5, 6-9v, 20-21, 44v-47.

s2 $\mathrm{Na}$ consulta sobre o $2^{\circ}$ caderno chegou-se a escrever: «E esta Ordem ser a primeira miliçia que ouve neste Reyno, E que o libertou do poder dos Mouros com muitos, E heroicos feitos» - Ibidem, fl. 32.

53 Ibidem, fl: 28. 
ta era outro elemento preparatório do capítulo geral. Caberia certamente a este reaproveitar os textos produzidos no âmbito daquela. Era um novo modelo de trabalho, no qual a reunião magna apenas ratificava o labor que a antecedera.

Perderam-se todos os quatro cadernos enviados ao monarca. Restam apenas cópias autênticas das consultas que os acompanharam. Pelo menos desde a carta régia de 4 de Setembro de 1613 que estas deixaram de ser analisadas pela Mesa da Consciência, antes de transporem a fronteira. O referido documento estabeleceu que fossem ao governo sediado em Lisboa, «E que vendoas nelle, sem as comonicar à outro algum tribunaL ${ }^{54}$, deviam depois ser remetidas ao rei. Tal mudança é um ponto a realçar. Traduzia algum cuidado na gestão política do evento. Era uma forma de evitar a Mesa da Consciência, o que não era inconsequente. Parece, todavia, pouco provável que se destinasse a permitir a livre expressão do ponto de vista dos cavaleiros. É verosímil, ao invés, que se destinasse a contornar a defesa oficial dos privilégios dos cavaleiros que a instituição era obrigada a fazer. Para todos os efeitos, era também um órgão da. Coroa, o que de alguma forma a comprometia.

Nestas consultas destacavam-se os pontos nos quais se reivindicavam maiores alterações. Relativamante ao primeiro caderno, realçava-se a preocupação com o facto de Filipe III ainda não ter feito o juramento das Ordens Militares. Pretendia-se «que se ponha em difinição que tanto que for eleito Mestre, E em principio do governo de cada hum dos administradores perpetuos, onde quer que estiver toma logo Juramento nas maos de huns Comendadores das tres Ordeñs militares eleitos $\mathrm{E}$ mandados a isto pello Conselho de Ordeñs, E que antes de taL solemnidade não possa o mestre, ou Governador mandar cousa alguã açerca do dito governo" $\$ 5$. Era uma medida preventiva. A par deste assunto ainda se referiam as rendas do Convento de Avis, o provimento dos benefícios simples e a atribuição de insígnias episcopais ao Prior-mor.

A $2^{a}$ parte da regra reportava-se aos cavaleiros e comendadores e acentuava a tónica de que se tratavam de pessoas isentas não só da jurisdição secular, como da eclesiástica e de todo o tributo e direito real que por qualquer via fosse imposto. O objectivo era apelar a que Filipe III como rei declarasse que interpretava de outro modo a Ordenação [Ord. Fil., L ${ }^{\circ} 2$, Tít. XII, §1], que limitava o foro privativo às questões crimes e às cíveis decorrentes das primeiras ${ }^{56}$. Pretendia-se isenção em qualquer pelouro.

54 Ibidem, fl. 21.

s5 Ibidem, fl. $15 \mathrm{v}$.

s6 A limitação aos feitos crimes foi introduzida em 1536 e foi primeiro incorporada nas Leis Extravagantes, de Duarte Nunes de Leão (Lisboa, Antonio Gonçalvez, 1569, Parte II, tít.III, lei I e lei IV). Em Castela acontecia o mesmo - cf. POSTIGO CASTELlANOS, Elena: Honor y privilegio en la Corona de Castilla: el Consejo de las Órdenes y los caballeros de hábito em el s. XVII, Soria, Junta de Castilla y León, 1988, pp. 230-232; Idem, "Monarca frente a Maestre o las Órdenes Militares en el proyecto político de la nueva dinastía: los decretos de 1714 y 1728", in Antigo Régimen y Liberalismo:

Hispania, LXIV/1, núm. 216 (2004) 95-116 
$\mathrm{Na} 3^{\mathrm{a}}$ parte da regra tratou-se do Convento de Avis. Para alguns assuntos foram vistas definições de «outras milicias», bem como o regimento e visitações desta ${ }^{57}$. Pela primeira vez referia-se o colégio que se projectava fazer em Coimbra e que ficou conhecido como o "Colégio dos Militares». Enviaram-se os estatutos destinados ao mesmo, feitos pelo Prior-mor, a mando da Mesa da Consciência. Considerava-se que era obra «mui necessaria à authoridade, E bem das Ordens Militares», pois destinava-se a produzir letrados, como havia noutros institutos, capazes de defender e dar reputação a estas milícias. Todavia, propunha-se que em lugar de um mesmo instituto para as duas milícias (Avis e Santiago), com seis colegiais de cada uma, se optasse por dois colégios autónomos. Segundo era dito, poderia ser difícil conciliar pessoas de diferentes hábitos numa só instituição. Para isto dever-se-iam aplicar 500 cruzados de renda de cada Ordem. Deste modo também se evitava impor novos encargos nas comendas, um aspecto que devia preocupar os comendadores, uma vez que já havia um diploma papal a sancionar o novo ónus.

A $4^{\mathrm{a}}$ parte da regra foi enviada antes da terceira, «porque se estavão vendo certos papeis, $\mathrm{E}$ esperando por outros " ${ }^{58}$, justificava-se. Abarcava questões diversas, desde recomendações para evitar as dispensas em matéria de sangue até tópicos sobre o modo "como se hade entender e praticar à exempção dos dizimos», passando pela observação que os comendadores deviam residir algum tempo nas suas comendas ${ }^{59}$.

O último caderno da regra, enviado também a 8 de Março de 1614, apresentava «hum index dos privilegios, jndultos, graças, $\mathrm{E}$ jndulgencias concedidas em particular a esta Ordem de Avys E de outros concedidos as Ordeñs, E religioiñs de que ella por comonicação participa, E goza» ${ }^{60}$. Ainda se rematava pedindo que, como a Ordem não usufruía dos privilégios das mendicantes, que tal regalia fosse impetrada a Roma, bem como a licença para o Prior-mor poder crismar em Noudar e Barrancos, junto à fonteira (zonas de nullius diocesis e dependentes do Convento de Avis).

$\mathrm{Na}$ última consulta recapitulava-se o analisado em toda a junta. Para remate, pedia-se um conselho de Ordens separado da Mesa da Consciência, onde os assuntos fossem tratados pelos comendadores e cavaleiros mais idóneos, «com o zelo que naturalmente tem os membros à conservação de Seu corpo ${ }^{61}$. Pediase também capítulo geral para confirmar os estatutos elaborados. Justificavase, igualmente, que não fora possível terminar mais cedo, pelos muitos papéis, bulas e assentos de visitações que se tornara indispensável ver.

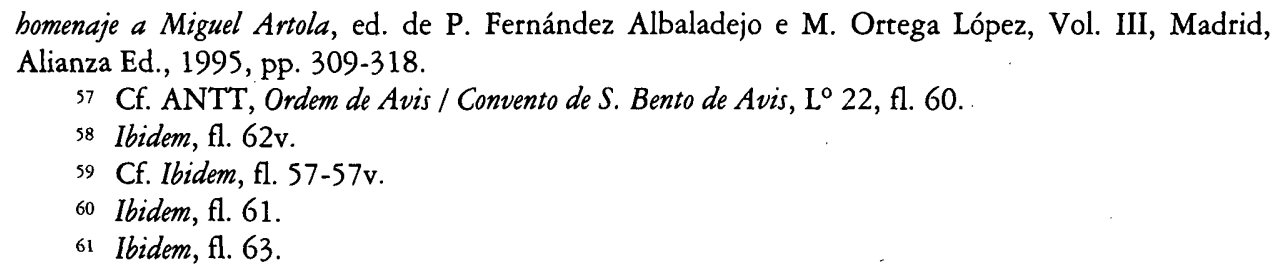


As juntas das Ordens de Cristo e Santiago também se realizaram, embora praticamente se desconheça a quase totalidade dos conteúdos tratados. Pelo menos a de Cristo teve lugar no Convento de S. Domingos, em Lisboa, e iniciouse em Março de $1613^{62}$; a de Santiago começou em Fevereiro e acabou em Maio do ano seguinte, $1614^{63}$. Tal como a de Avis, não se sabe onde se realizou.

\section{A Visita de Filipe III E OS CAPÍtulos GeRAis DAS TRÊS ORDENS Mili- TARES}

Quando, finalmente, em 1619, Filipe III visitou Portugal, acabou por reunir capítulos gerais das três Ordens, como há muito se apontava. Nas Cortes de Lisboa desse ano, pelo menos a Nobreza também assim o pedira ${ }^{64}$. A visita consubstanciava, assim, um dos seus objectivos políticos: manifestar a presença régia, como símbolo arbitral de justiça, junto das diferentes entidades que compunham o Reino de Portugal, uma atitude importante no contexto de uma monarquia compósita.

A ideia foi concretizada já na fase em que o monarca pretendia regressar a Castela. Pelo que se sabe dos preparativos, tudo foi feito de modo apressado: Chegou-se mesmo a pôr a hipótese de realizar tais assembleias no convento de $\mathrm{S}$. Francisco, em Lisboa, durando cada uma três dias, mas não foi a solução que vingou ${ }^{65}$. Mesmo assim, Filipe III anunciou que estaria presente em todos os capítulos, o que implicava grandes deslocações.

O de Avis foi o primeiro a iniciar-se. Realizou-se em Setúbal, na Igreja de Santa Maria da Graça, a 2 de Outubro, embora tivesse sido primeiro calendarizado para 26 de Setembro ${ }^{66}$; dois dias depois abriu, em Palmela, o de Santiago. Já no itinerário de regresso, o rei foi a Tomar, onde se reuniram os membros da Ordem de Cristo, em 16 de Outubro. Seguiu depois rumo a Badajoz, onde chegou a 23, depois de ter passado por Ponte de Sor, Alter do Chão, Arronches e Campo Maior ${ }^{67}$.

Ao que parece, apenas a abertura destes capítulos ocorreu no local citado e com a presença régia. Também perante o monarca foi feita a eleição dos definidores. Depois disso, reuniram tais mandatários em Lisboa. O definitório da Ordem de Cristo durou 6 meses ${ }^{68}$ e foi presidido pelo Prior Geral do Convento de Tomar, que registou uma pequena memória queixosa sobre o evento: «Sey

62 Cf. ANTT, Ordem de Cristo / Convento de Tomar; Mç. 55.

63 Cf. BN, Cód. 10559, fl. 80.

64 Cf. BA, 44-XIII-32, fl. 6v.

65 Cf. ANTT, Mesa da Consciência, $\mathrm{L}^{\circ} 303$, fl. 2v-3.

66 Cf. ANTT, Ordem de Avis, doc. 1129.

67 Vide, por todos, SILVA, Francisco Ribeiro da: «A viagem de Filipe III a Portugal: itinerários e problemática», Revista de Ciências Históricas, Porto, II, 1987, pp.223-260.

68 Até 7 de Abril de 1620 - cf. ANTT, Ordem de Cristo / Convento de Tomar, $\mathrm{L}^{\circ} 312$, fl. $214 \mathrm{v}$. 
que foy muito tempo o que gastey, e que fiz grandes gastos estando Em Lisboa de Ordinario com muitos criados, e Cavalgaduras, e com muitos Religiosos, e muitos hospedes, que fazião quando menos iguais gastos, dos Ordinarios, porque âLem dos nossos Religiozos, outros de outras Religiõez, e fidalgos, e Senhorez, que Me fazião merce de vizitar, $\mathrm{E}$ eu os agazalhava dandolhe mesa» ${ }^{69}$. Reunia-se tal definitório na Mesa da Consciência, o de Santiago no Mosteiro de S. Roque ${ }^{70}$. Quanto ao de Avis apenas se sabe que se congregava em Lisboa. No entanto, é de admitir a hipótese de se terem juntado também em S. Roque, tanto mais que o secretário era o mesmo da Ordem de Santiago.

De alguma maneira nestas instituições imitavam-se as reuniões das Cortes do Reino, que também recorriam a estes cenóbios de Lisboa.

Cada vez mais os longínquos conventos se transformavam em espaços meramente simbólicos. As grandes decisões tomavam-se ou na corte dos Austrias ou em Lisboa. Em Portugal, o resto estava a converter-se em periferia, mesmo quando se tratava de Ordens Militares, com um passado ligado à Reconquista do território.

O definitório de Avis começou apenas a 13 de Novembro e terminou a 20 de Junho do ano seguinte. Ao abrir dos trabalhos, analisou não só os apontamentos que recebera dos membros da Ordem, quanto os papéis da junta de 1613-1614 e o parecer que sobre eles dera a Mesa da Consciência ${ }^{71}$. Quer D. Lopo de Sequeira Pereira, já bispo de Portalegre ${ }^{72}$, quer os dois comendadores, D. Jerónimo Coutinho e D. Carlos de Noronha, voltaram a ser intervenientes. Não surpreende, pois, que se tenha retomado o material citado. A regra preparada na junta de 1613-1614 foi analisada e recebeu a confirmação dos definidores, tal como se escreveu na mesma, em letra de forma ${ }^{73}$. A este conjunto apenas foram acrescentadas 53 definições, feitas entre 1619 e 1620 , e um conjunto de regimentos (alguns se calhar já feitos antes). Tudo isto foi aprovado em Madrid, a 30 de Maio de $1627^{74}$, tal como os textos reformadores das Ordens de Cristo e Santiago.

Os primeiros estatutos a serem impressos foram os de Cristo, em 1628. Os de Avis apareceram em 1631, apesar de uma advertência feita na censura do Desembargo do Paço: «Que se possam imprimir estas Diffinições, com declaração, que o deduzido nellas não prejudicará à jurisdicção de Sua Magestade, não avendo confirmação sua, como rey do que a ella tocar». $O$ contido nesta regra e definições de Avis era de facto ousado. Revelava, claramente, os interes-

\footnotetext{
69 Assim se justificava que tenha recebido do rei 2000 cruzados, a seu pedido - Ibidem, $\mathrm{L}^{\circ} 34$, fl. $27 \mathrm{v}-28$.

70 Cf. BN, Manuscritos avulso, Cx.90, doc.14, fl. 16.

71 Cf. ANTT, Mesa da Consciência, L ${ }^{\circ} 1$, fl. 201-201v.

72 Assistiu com o estatuto de prior-mor, através de uma provisão régia - Regra da Cavallaria..., cit., tít. I, cap.VIII.

73 Cf. Ibidem, tít.I, cap. VII, fl.14.

74 Cf. Ibidem, fl. $153 \mathrm{v}$.
} 
ses dos cavaleiros e da Ordem. Nas de Cristo não se ia tão longe. Talvez porque o ponto de partida estava mais próximo dos interesses da Coroa, patentes no texto matricial de 1589. Mesmo assim, o impresso causou alguns embaraços, nomeadamente no respeitante à isenção de dízimos; problema este que se arrastou no período pós-Restauração ${ }^{75}$. Todavia, numas e noutras, o empenhamento do entretanto já Deputado da Mesa da Consciência, D. Carlos de Noronha, para que se imprimissem fora muito grande ${ }^{76}$.

Quanto ao texto da Ordem de Santiago, adiou-se a sua divulgação através da tipografia. Em 1633, pediu-se inclusivemente a D. Carlos de Noronha que integrasse uma junta, destinada ao ajustamento do definitório de 1619/1620 com a regra de Santiago. As dúvidas que surgissem deviam ser endereçados ao Desembargo do Paço. Esta junta pouco fez da sua tarefa e o assunto foi protelado, muito embora fosse de vez em quando lembrado na correspondência entre o centro político e os poderes sediados em Lisboa 77 .

Só em 1694 os textos de Santiago foram impressos, pela iniciativa de um impressor e aparentemente sem licença do Mestre ${ }^{78}$. Republicava-se a regra feita em 1542 e as definições resultantes do capítulo geral de 1619, nada mais.

\section{EPÍlOGO: INTERESSES, REFORMAS E A IMAGEM DAS ORDENS MilitARES PENINSULARES}

Reformar constituía um verdadeiro «topos» na cultura política do Antigo Regime, decorrente da experiência das instituições religiosas. Desta forma, não deve surpreender o apelo frequente a tal prática.

No caso analisado, importa sobretudo recapitular que tipo de interesses e imagens alimentaram as reformas descritas e de que forma estas reconfiguraram as Ordens Militares portuguesas.

A união das Coroa favoreceu que se comparasse a realidade das milícias portuguesas e castelhanas. Já desde a Idade Média que frequentemente se encaravam as segundas como modelo, num ou noutro aspecto - quanto mais não fosse ao nível dos privilégios que se podiam solicitar a Roma. Alegava-se, amiúde, que determinada Ordem portuguesa beneficiava de uma regalia concedida a uma castelhana. Frequentemente copiavam-se os estatutos. Agora ia-

75 Cf. Olival, Fernanda: As Ordens Militares, p. 51; Freitas, Joaquim Ignacio de, ed.: Colleç̧ão chronologica de leis extravagantes, posteriores à nova compilação das Ordenações do Reino, publicadas em 1603, T. I, Coimbra, Real Imprensa da Universidade, 1819, pp.503-506.

76 Cf. ANTT, Mesa da Consciência, $\mathrm{L}^{\circ} 302$, fl. 11-11v.

77 Cf. Ibidem, $\mathrm{L}^{\circ} 33$, fl. 68v-69, 224v-225v; L $\mathrm{L}^{\circ} 34$, fl. 19, 40v, 120-120v, $164 ; \mathrm{L}^{\circ} 36$, fl. 89v9; ANTT, Mesa da Consciência - Ordens Militares - Papéis Diversos, Mç. 24, doc. 157-160.

78 Cf., na licença do Desembargo do Paço, o parecer do procurador da Coroa, impresso ao abrir o texto da Regra, estatutos, definição e reformação da Ordem e Cavalaria de Santiago de Espada, Lisboa, Miguel Manescal, 1694.

Hispania, LXIV/1, núm. 216 (2004) 95-116 
se mais longe. Como o Mestre era o mesmo em todo o espaço peninsular ${ }^{79}$, era um estímulo para reforçar os paralelismos e, como consequência no plano argumentativo, as reivindicações. Acicatava esta postura o tópico construído em torno da ideia que se tratavam de institutos idênticos, mas em situação desigual. As Ordens portuguesas demonstraram, num discurso de teor peticionário e desde o limiar do período dos Áustrias, que gozavam de pior condição, apesar de possuírem maior número de comendas. $\mathrm{Na}$ junta de 1589 lembrara-se a Filipe II que não convinha distribuir tantos hábitos de Cristo e a gente sem qualidade, pois contribuía para o abatimento da milícia mais relevante em Portugal. Justificava-se a observação com a situação modelar das castelhanas: «Desculpa esta lembrança o exemplo digno de perpetua memoria, da inteireZa E Justiça com que S.Md. neste particular nos reinos de Castela conserva, E acrescenta a honra das ordens de Sanctiago, Alcantara; E Calatrava, cujos habitos até hoje possuem somente as nobrezas, E Limpas fidalguias daquelles reinos. E nestes de Portugal tambem seus, podese com magoa dizer, que se fizerão os habitos comus a todos (...). Assi que degenerarão os habitos em Portugal, E suas insignias ia não representão o que lhes he devido» ${ }^{80}$.

Nas Cortes de Tomar (cap. XVIII do Povo), na junta de reforma da Ordem de Cristo do reinado de Filipe II, na junta de Avis de 1613-1614 e nos definitórios de 1619 pediu-se um conselho de Ordens para Portugal. O referencial era o castelhano. Propunha-se que os assuntos das Ordens fossem retirados da Mesa da Consciência. Na realidade, este pedido vinha já do capítulo da Ordem de Cristo de 1573. Neste ter-se-á solicitado «que S. Md. faça hũ conselho desta ordem [Cristo], que não seja a mesa da consciencia, onde se despachem as cousas tocantes à ordem, $\mathrm{E}$ presida nelle hũ comendador da ordem, com Letrados do mesmo mestrado, E que a forma $\mathrm{E}$ jurdição que S.Md. ouver de dar a este conselho, lhes faça merce asentala com os deffindores della» ${ }^{81}$.

Um ponto forte de oposição à Mesa da Consciência consistia no facto de muitos dos seus membros não serem cavaleiros, nem freires professos das Ordens Militares. Tal particularidade teria implicações, quer no exercício da justiça punitiva, quer no controlo da reprodução do grupo que constituíam os filiados nas Ordens Militares. Aliás, pelo que se sabe, este assunto terá sido levantado no último capítulo geral referido, dez anos depois de D. Sebastião ter obtido o diploma pontifício das três instâncias em matéria judicial. Desta forma, dos juízes das Ordens era permitido agravo para a Mesa da Consciência e desta era possí-

79 Exceptuada a Ordem de Malta. A Ordem de Montesa (da Coroa de Aragão) apenas em 1592 ficou efectivamente vinculada à Coroa castelhana, embora a bula estivesse disponível desde 1587 - cf. ROBRES, Fernando Andrés: «Garcerán de Borja, Felipe II y la tardía incorporación del Maestrazgo de la Orden de Montesa a la Corona. Los hechos", in Iglesia y Sociedad en el Antiguo Régimen, MARTïNEZ RUIZ, Enrique, y SUAREZ Grimön, Vicente eds., Vol.I, Las Palmas, Universidad de Las Palmas de Gran Canaria, 1995, pp. 409-420.

80 BN, Cód. 13216, fl.24.

81 Assim se relatava a questão por volta de 1589 - Ibidem, fl.104v. 
vel apelar para o Mestre. Tal poder levava a que se almejasse que - em segunda instância - os juízes fossem apenas cavaleiros.

Todavia, com este tipo de pedido, o objectivo último seria separar claramente a jurisdição real da do mestre, como se realçou em 1614, no âmbito da junta de reforma da Ordem de Avis ${ }^{82}$. No definitório da Ordem de Santiago, em 1620 , este ponto fulcral tornou-se claro, quando se afirmava que os tribunais reais julgavam que dar a jurisdição das Ordens ao monarca era o mesmo que atribui-la ao mestre ${ }^{83}$. Receava-se cada vez mais a perda da autonomia, o efeito manipulador do centro político e a simples confusão de jurisdições, embora nem sempre tal facto fosse claramente dito. Havia, sobretudo, um jogo subtil.

Não terá sido por acaso que, na junta de 1589 , onde estiveram presentes pessoas da exclusiva nomeação régia, o assunto do Conselho de Ordens tenha sido votado negativamente. Quatro votos manifestaram-se desfavoráveis à saída destes institutos da Mesa da Consciência. Alegavam que o tribunal passara inclusive a chamar-se «Mesa da Consciência e Ordens» quando passou a tratar dos assuntos das três milícias e que «te agora se tem feito nella justiça, a qual parece Se fará livremente per pessoas, que não são das mesmas ordens, nem interessadas nos bens dellas» ${ }^{4}$. Dois outros foram adeptos do novo conselho, «como havia em Castela», dizia-se; os dois restantes preferiam adiar o caso até novo capítulo geral. Certamente o assunto foi abordado por se tratar de uma temática recorrente entre os grupos ligados às Ordens e com maior participação política.

$\mathrm{Na}$ junta de Avis encerrada em 1614 sobressaia a postura contrária: «nos reynos de Castella, se fez logo tribunal de Ordeñs destincto, e separado, como hoje ha, no qual se tem defendido os privilegios, E conservada a authoridade das Ordeñs em forma que sendo de menos importancia que as de Portugal estão em muito diferente predicamento $\mathrm{E}$ estima, $\mathrm{E}$ quando não ouvera mais que este exemplo, bastava para fazer nossa petição Justa, E não parecer studada de novo» 85 .

Também nesta junta propunha-se, pela primeira vez, uma alternativa mais moderada, se não se deferisse este pedido: que ao menos o Presidente e três dos cinco votos da Mesa da Consciência fossem pessoas das três Ordens ${ }^{86}$. E rematava-se: «Pello que ventilandose esta materia do primeiro dia que a junta comesou tratar os negocios da Ordem sempre se entendeo que so este era o unico remedio para as Ordeñs se restaurarem do estado em que estão postas esquecidas de Sua primeira origem, quebrantadas em a observancia de suas regras, enfraquecidas em seus privilegios, estragadas em suas jurisdiçoiñs, deminuidas em o patrimonio que acquiriram com o sangue de Seus professores» ${ }^{87}$. Para

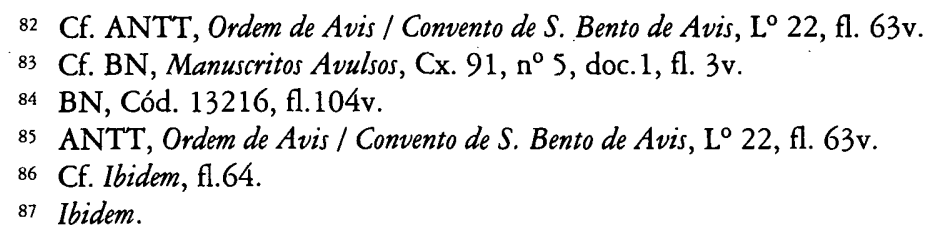

Hispania, LXIV/1, núm. 216 (2004) 95-116 
enfrentar as despesas que o novo organismo pudesse causar, indicava-se que bastava aplicar uma comenda de cada Ordem para este efeito. Curiosamente, no definitório de 1619 , retomou-se ipsis verbis este pedido ${ }^{88}$. Ter-se-á mesmo copiado uma parte significativa do texto de 1614 .

No caso de definitório da ordem de Santiago, em 1620, considerava-se que, na ausência do rei, era mais um ponto para reforçar a protecção às Ordens (nomeadamente contra os ordinários), mediante este Conselho. Lembra-se que «o patrimonio Real deste Reino não tem couSa mais importante com que possa satisfazer os serviços que se fazem a Coroa que o patrimonio e beñs das ordeñs $\mathrm{E}$ que quando no Priorado do Crato $\mathrm{E}$ abbadia de Alcobaça, ha tribunaes particulares em que se trata de Seu governo com muita mais rezão Convem que o aja desta ordeñs separado da meSa da Consciencia» ${ }^{89}$. A comparação neste caso não se limitava a Castela. Era também uma questão de pesos relativos no interior do Reino e, como tal, de estatuto, por parte de Ordens que se auto-representavam inferiores apesar da sua grandeza.

Ainda neste mesmo definitório, o paralelo com Castela voltava o ocorrer, quando, a propósito das habilitações, se pretendeu introduzir os comissários ${ }^{90}$, que até então não existiam em Portugal.

Globalmente, durante a tutela de Filipe II e sobretudo com Filipe III desenharam-se reformas, tendo em vista alterar o texto normativo fundamental de cada uma das três Ordens. Os definitórios de 1619-1620 foram a estes respeito decisivos, na medida em que recuperaram muito do trabalho anteriormente feito em juntas, mas só deste ponto de vista.

A diversos níveis são notórias as diferenças entre estes polémicos estatutos e os textos normativos que os antecederam, feitos durante a primeira metade do século XVI. Os definitórios de 1619 corresponderam a uma tentativa de reafirmação do estatuto destas milícias e dos respectivos privilégios. Revelavam acima de tudo os interesses das Ordens.

O facto dos definitórios de 1619-20 partirem de experiências e de textos de um passado recente (juntas invocadas), o facto de se reunirem em Lisboa e em locais muito próximos uns dos outros, certamente permitiu posturas tendencialmente convergentes nos três Mestrados. O papel de D. Carlos de Noronha (†1645), formado em Direito Civil, terá sido também importante. Conhecia bem as Ordens e era seu defensor. Em 1625 chegaria a Deputado da Mesa da Consciência e em 1641 a Presidente da mesma instituição.

A experiência castelhana adaptava-se muito bem a este esforço reivindicativo. As comparações eram já anteriores a 1580 , mas a união das Coroa veio incentivá-las e reforçá-las. Eram aproveitadas para advogar maior autonomia destes corpos no interior do Reino, apontando as Ordens castelhanas como exemplo.

88 Cf. ANTT, Mesa da Consciência, L L 1, fl. 203-204.

89 BN, Manuscritos Avulsos, Cx. 91, nº 5, doc.1, fl.4.

90 Cf. Ibidem, fl.1. 
Esse era, todavia, apenas o ponto de vista das Ordens. Para a realeza a questão punha-se noutros moldes. Filipe II tentou usá-las o mais que pôde para pagar serviços e Filipe IV acabou por fazer o mesmo, cada um à sua maneira. Sobretudo na década de 1630, Filipe IV tentou disciplinar os seus servidores e a nobreza em geral, ao atribuir hábitos e comendas mediante obrigações que deviam ser, quase sempre, previamente satisfeitas e que não correspondiam aos tópicos que impusera D. Sebastião. Eram reformas feitas subtilmente, sem as formalidades habituais e sem ouvir os cavaleiros. Iniciava-se claramente outra fase na vida das Ordens Militares Portuguesas. A partir daí, a força dos seus seus numerosos membros não sería já suficiente para travar o poder do rei-mestre. Nesse sentido, as mudanças sob os Áustrias foram decisivas: quase esgotaram a capacidade reivindicativa dos cavaleiros. Filipe III foi dos poucos monarcas que condescendeu em ouvi-los, ao permitir que fizessem parte de juntas sobre as Ordens e ao autorizar capítulos gerais, mas a experiência não voltaria a repetir-se. 